\title{
Fighting Fatigue in Military Forces
}

\author{
Babak Daneshfard (iD ${ }^{1}$ and Nafiseh Hosseini Yekta (iD ${ }^{2,{ }^{*}}$ \\ ${ }^{1}$ Traditional Medicine Clinical Trial Research Center, Shahed University, Tehran, Iran \\ ${ }^{2}$ Department of Persian Medicine, Faculty of Medicine, AJA University of Medical Sciences, Tehran, Iran \\ "Corresponding author: Department of Persian Medicine, Faculty of Medicine, AJA University of Medical Sciences, Tehran, Iran. Email: nhyekta@yahoo.com
}

Received 2020 May 05; Revised 2020 July 07; Accepted 2020 July 07.

Keywords: Fatigue, Integrative Medicine, Persian Medicine, Delphinium denudatum, Jadwar

\section{Dear Editor,}

One of the most common disorders related to military service is fatigue and weakness of the physical and mental strength. Fatigue is a feeling of exhaustion and lack of energy that interferes with physical and cognitive functions. This inability to perform and maintain optimal performance has been attributed to a number of factors, including disruption of the sleep-wake cycle, prolonged stressful state, and high workload (1).

Fatigue can cause many problems for the military forces, especially during military operations. Battle fatigue can reduce the ability of the forces by up to $50 \%$ (2). According to the studies, the weight of the equipment carried by soldiers is one of the causes of their fatigue and, consequently, their injuries. On the other hand, the weight of this equipment has been increased over the time (3). Hence, it will be useful and, of course, necessary to find a solution for increasing the strength of the soldiers and preventing this complication as much as possible to eliminate their fatigue in the shortest possible time.

Considering the current approach of integrative medicine in most parts of the world, herbal medicine as a popular branch of Complementary and Alternative Medicine (CAM) is commonly used for various disorders (4). In this regard, Persian Medicine (PM), as one of the oldest comprehensive medical schools with a history of thousands of years, has introduced herbal medicines for various ailments in its therapeutic approach (5).

Delphinium denudatum Wall. (Ranunculaceae), also known as Jadwar (Mah-Parvin in Persian) (Figure 1), is a medicinal herb with various properties (6). In PM, Jadwar has been used as a tonic agent for increasing mental and physical stamina in addition to its usage as poison detoxification and a pain-relieving drug (7).

Considering the aforementioned, we conducted a ran- domized placebo-controlled clinical trial in the students of AJA University of Medical Sciences to evaluate the efficacy of Jadwar root powder (in a capsule dosage form) in fighting fatigue. A total number of 64 healthy participants were evaluated in this study using the Persian version of the Multidimensional Fatigue Inventory(MFI) questionnaire as a standard self-report instrument for the assessment of fatigue. Based on the results of this trial, using 500 milligrams of Jadwar root powder for 15 consecutive days significantly improved the perception of participants regarding their mental, physical, and emotional functionality (8). Various active ingredients in Delphinium denudatum, including flavonoids (such as quercetin) and fatty acids, may play a role in its anti-fatigue effect; however, it should be further investigated.

Such a natural product could be easily used in military forces in the dosage form of capsule. This product is feasible for them to carry and consume in different military situations to increase their functionality. Further investigations considering objective outcome measures should be conducted in other groups of military forces to rigorously confirm its safety and efficacy.

\section{Footnotes}

Authors' Contribution: B. Daneshfard wrote the primary draft of the paper and N. Hosseini Yekta revised and approved the final version of it.

Conflict of Interests: The authors declare that they have no conflict of interest.

Funding/Support: None. 

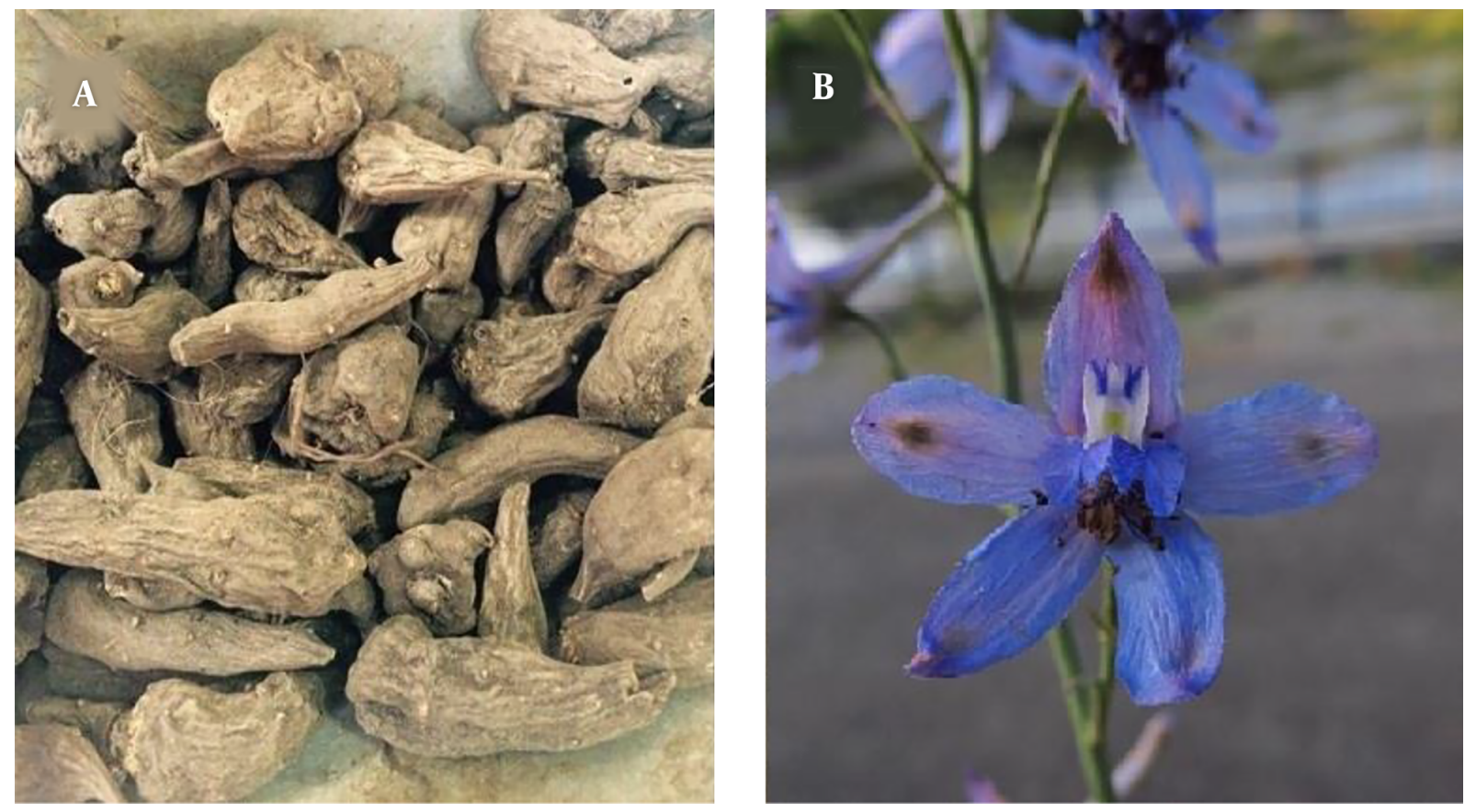

Figure 1. Delphinium denudatum (Jadwar) A: root, B: flower

\section{References}

1. Caldwell JA, Caldwell JL, Thompson LA, Lieberman HR. Fatigue and its management in the workplace. Neuroscience \& Biobehavioral Reviews. 2019;96:272-89.

2. Hazen S, Llewellyn C. Battle fatigue identification and management for military medical students. Military medicine. 1991;156(6):263-7.

3. Orr RM, Johnston V, Coyle J, Pope R. Reported load carriage injuries of the Australian army soldier. Journal of occupational rehabilitation. 2015;25(2):316-22.

4. Golshani SA, Daneshfard B, Mosleh G, Salehi A. Drugs and pharmacology in the Islamic Middle Era. Pharm Hist (Lond). 2015;45(3):64-9.
5. Atarzadeh F, Daneshfard B, Dastgheib L, Jaladat A, Amin G. Early description of diet-induced blistering skin diseases in medieval Persia: Avicenna's point of view. Skinmed. 2016;14(5):367-70.

6. Nizami Q, Jafri MA. Unani drug, Jadwar (Delphinium denudatum Wall.)-a review.Indian Journal of Traditional Knowledge. 2006;5(4):4637.

7. Alavi S.Makhzan Al-adviyah (The Storehouse of Medicaments). Tehran: Intisharat va Amoozesh Enghelab Press; 2009.

8. Daneshfard B, Yekta NH, Khoshdel A, Heiran A, Cheraghi R, Yarmohammadi $H$. The effect of Delphinium denudatum (Jadwar) on fatigue: A randomized double blind placebo-controlled clinical trial. Complementary therapies in medicine. 2019;46:29-35. 